\title{
Pemahaman dan Keterlibatan Masyarakat Papua dalam Kargoisme
}

\author{
Roberth Ruland Marini \\ Sekolah Tinggi Alkitab Jember, Jawa Timur \\ robbymarini5040@gmail.com
}

DOI: https://doi.org/10.47167//hharis.v3i1.39

\begin{abstract}
The cargo cult is a pattern of belief and is considered to be the initial religion of the Papuan people, this is deeply embedded in the Papuan people. They have become Christians but also at certain times take part in ritual practices related to cargoism. The purpose of the study is to have a detailed understanding, also of the Sorido village community response, about cargoisme and also the consequences of what they experience as adherents of this belief. In the research analysis conducted was a qualitative analysis, with 16 participants answering 12 questions from 3 indicators sourced from one variable. Then the understanding and involvement of the Sorido village community in Biak Numfor Papua district on cargoisme has shown ontetic data that is in accordance with data calculation procedures, so it is known that $12.5 \%$ of participants trust cargoism and $87.5 \%$ of participants do not trust cargoism. And $87.5 \%$ of participants believed in the legend of Manarmakeri while 12.5\% of the participants did not believe in the legend of Manarmakeri.
\end{abstract}

Keywords: cargo cult; Christian; evangelism in Papua; Papua culture

\begin{abstract}
Abstrak
Kultus kargo adalah pola kepercayaan dan diangap sebagai agama yang awal dari orang Papua, hal ini sangat tertanam di dalam diri orang Papua. Mereka telah manjadi Kristen tetapi juga masih pada waktu-waktu tertentu turut mengambil bagian dalam praktik-praktik ritual yang berhubungan dengan kargoisme. Tujuan penelitian agar ada pemahaman yang detail, juga mengetaui respon masyarakat kampung sorido, tentang kargoisme dan juga konsekuensi apa yang dialaminya sebagai penganut kepercayaan ini. Dalam penelitian analisis yang dilakukan adalah analisis kualitatif, dengan 16 partisipan menjawab 12 pertayaan dari 3 indikator yang bersumber dari satu variabel. Maka pemahaman dan keterlibatan masyarakat kampung Sorido kabupaten Biak Numfor Papua tentang kargoisme telah menunjukan data ontetik yang sesuai dengan prosedur perhitungan data, maka diketahui bahwa 12,5\% partisipan mempercayai kargoisme dan 87,5\% partisipan tidak mempercayai kargoisme. Dan $87,5 \%$ partisipan mempercayai legenda manarmakeri sedangkan $12,5 \%$ partisipan tidak mempercayai legenda manarmakeri.
\end{abstract}

Kata kunci: budaya Papua; kargo; kargoisme; penginjilan Papua

\section{PENDAHULUAN}

Tanah Papua berada di wilayah paling timur Indonesia, yang dihuni oleh ras Melanesia, di daratan provinsi Papua dan Papua Barat, sampai ke kepulauan-kepulauan di Samudra Pasifik, yang memiliki suatu kepercayaan kultus kargo dan sangat mempengaruhi jiwa dan seluruh sistem kebudayaan masyarakat setempat. Keberadaan manusia Papua di Melanesia adalah sebai berikut; istilah Melanesia artinya pulau-pulau orang hitam. Secara geografis, wilayah bangsa Melanesia dimulai dari bagian timur laut Australia, di bagian 
barat dari kepulawaan raja ampat, kepulawan teluk cendrawasih pulau New Guinea, kepulawan bismark, kepulawan salomon, Santa Grus, New Hibride dan Lusiada. Ciri-ciri ras Melanesia kulit berwarna hitam dan berambut keriting. ${ }^{1}$

Penduduk di kepulauan Melanesia digolongkan ke dalam rumpun Papua Melanesia yang berasal dari ras induk negroit. ${ }^{2}$ Kajian-kajian yang didasarkan dalam pandangan Darwinisme Evolusionistik dan Difusionistik telah banyak memberikan keterangan mengenai asal-usul bangsa Melanesia. Windsor Earl dalam ekspedisi di wilayah ini melaporkan bawah orang Papua adalah suatu tipe ras yang tersendiri ia mengusulkan dengan pertimbangan varian-varian tertentu seperti perawakan tingi dan warna kulit. Walaupun ia mengindetifikasi orang Papua sebagai salah satu ras yang tunggal, Windsor Earl menemukan bukti mengenai fariasi-fariasi keistimewaan itu dan ia mengaitkan bahwa New Guinea sedikitnya terdapat dua kelompok manusia yakni: kelompok pertama, kelompok yang berpostur tubuh pendek, menempati di bagian dalam Pulau New Guinea yang kemudian ia di sebut pygmies.

Kelompok kedua, sebulum dasawarsa Schweinfurth banyak penjelajah telah merayakan upacara mengenai penemuan mereka yang diyakini berasal dari pigmies afrika dan penduduk dari kelompok ini postur tubuhnya lebih besar atau kadang-kadang raksasa (gigantic). Mereka ini adalah penduduk suku-suku Papua yang menempati wilayah pantai. Wallaces dalam expedisinya yang mengunjungi Doreri Manokwari, setelah pertama kali ia melihat keadaan alam dan manusia di daerah itu, lalu ia mengatakan "saya sekarang pertama kali melihat orang-orang Papua di negeri mereka sendiri." Sunguh hal yang mengherankan dan baru, dalam suatu mahakarya Sang Pencipta, dengan menghadirkan suatu ras yang berbeda dengan ras lainya di negeri Cendrawasih Papua. Manusia Papua adalah manusia superior ras yang membutuhkan waktu yang lama untuk menerima perubahan.

Robert Screiter dalam bukunya Rancang Bangun Teologi Lokal berkata budaya adalah konteks konkrit tempat hal ini terjadi. Ia mewakili cara hidup untuk suatu masa dan tempat tertentu, dipenuhi dengan nilai-nilai, lambang dan makna yang menjangkau harapan-harapan dan mimpi-mimpi yang sering bergumul demi dunia yang lebih baik. ${ }^{3}$ Kultus kago adalah pola kepercayaan, dan diangap sebagai agama yang awal dari orang Papua hal ini sangat membekas dan sulit untuk dilepaskan oleh orang Papua, mereka telah menjadi Kristen tetapi masih juga pada waktu-waktu tertentu mempraktekan ritual-ritual tertentu kepada sang khalik yang disembah. Di Biak, Serui, Wandama, Sorong, Jayapura, daerah-daerah pegunungan Papua, aliran kepercayaan ini masih ada bahkan terus berkembang.

Ketika dilihat dari segi ideologi dan kepercayaan, di sini menunjukkan bahwa orang Papua tersebar dalam beberapa pola mitologi antara lain: Mitologi Koreri dalam budaya Biak Numfor dan Raja Ampat; Mitologi Pasai Kuri di daerah Nabire, Manokwari,

\footnotetext{
${ }^{1}$ A. Ibhahim Peyan, Kolonialisme dan Cahaya Dekolonissi di Papua Barat (Jayapura: Nentien fokos tt), 59 .

${ }^{2}$ Manasoben J. R, Sistem Politik Tradisional di Iriyan Jaya (Jakarta: LIPI-RUI, 1995), 23.

${ }^{3}$ Robert J Schreiter C. PP. S, Rancang Bangun Teologi Lokal (Jakarta: BPK Gunung Mulia, 1996), 37.
} 
Wondama dan Bintuni; Mitologi Dema dalam kebudayaan Marind Anim, Funerepits dalam budaya Asmat dan sekitarnya, Antuaripiti Bipiaripimera dalam kebudayan Kamoro; Mitologi Yeli dalam budaya Yali, Mek dan Hubula, Naruekul dalam budaya Hubula di lembah Baliem; Hai dalam budaya Amungme dan Nabelal-Habelal di dataran tinggi Papua, mulai dari Yali, Hubula, Lani, dan sekitarnya. ${ }^{4}$ Praktik-praktik ritual Kultus kargo masih dilakukan sampai sekarang, dengan mempersembahkan syair-syair pujian pengagungan (wor) kepada yang disembah, juga memberi persembahan makanan-makanan pilihan yang terbaik kepada yang kudus di sorga (Manseren Manggundi). ${ }^{5}$

Banyak menarik perhatian dalam kehidupan beragama orang Papua ialah seperti gerakan-gerkan koreri (koreri di sini gambaran dari firdaus atau sorga). Gerakan-gerakan itu bertolak dari mitos tentang manseren manggundi, (Manseren Manggundi sama seperti manarmakeri nama ini menunjukan tentang Tuhan) yang merupakan took zaman purbakala, yang memiliki rahasia kehidupan sejaterah yang bebas penyakit dan maut, tetapi karena sakit hati berangkat ke dunia Barat. Penduduk Papua yakin bawah suatu waktu Manggundi akan kembali dan sewaktu-waktu khusus pada saat-saat genting mereka terjun ke dalam kegiatan menghimpun makanan, lalu menari-nari dengan maksud mengusahakan kedatanganya, di bawah seorang konor, (konor adalah seorang nabi yang berbuat bagi orang-orang di kampung-kampung Papua). ${ }^{6}$ Jadi budaya kultus kargo di sini adalah, suatu upaya pengharapan orang Papua dalam penantian dari hari yang penuh pembebasan, damai sejaterah atau hidup dalam kemakmuran tanpa intimidasi dan penindasan.

Kebanyakan dari kenyataan-kenyataan dalam ritual kultus kargo, biasanya tampilan seorang konor dengan nubuatan-nubuatan apokaliptik tentang masa kejayan yang gilanggemilan di masa depan, di Tanah Papua. Penduduk di atas fasalfah ini, telah menjadi ideologi turun-temurun dalam suatu penantian panjang, apalagi di tengah-tengah runtuhnya integritas pemimpin bangsa di negara Indonesia telah menunjukan suatu keragu-raguan orang-orang Papua terhadap semua semua perencanaan pembangunan kesejaterahan bangsa. Kegagalan-kegagalan pemerintah dalam mensejahterakan rakyat di Papua, telah membuat pengharapan kargoisme mendapat spirit untuk kembali bangkit pada penduduk Papua Melanesia. Hal itu telah menyebabkan banyak program pemerintah kandas di tengah jalan. Kepercayaan rakyat Papua Barat terhadap pemerintah Indonesia semakin hari semakin hilang, akibatnya, terjadi kesenjangan antara rakyat Papua Barat dengan pemerintah Indonesia. $^{7}$

\section{METODE PENELITIAN}

\section{Teknik Pengumpulan Data}

Teknik pengumpulan data dilakukan dengan cara penelitian lapangan yaitu terjun langsung di lokasi penelitian untuk mendapatkan data yang dibutuhkan. Penelitian lapangan

${ }^{4}$ Ibid., 59.

${ }^{5}$ A. Ibrahim Peyon, Manusia Papua Negroid (Jakarta: Kelompok Studi Nirentohon PT. Kreatama, 2012), 36 .

${ }^{6} \mathrm{~F}$. C Kamma, De Messiaanic Koreri-Bewegingen in het biaks-noemfoorse (Den Haag: Culturgebied, 1954), 33.

${ }^{7}$ Yakobus F. Dumupa, Berburu Keadilan di Papua (Yogyakarta: Nuansa Aksara, 2006), 226. 
dilakukan dengan wawancara kepada 15 kepala suku satu Manawir di kampung Sorido Biak Numfor Provinsi Papua. Pengumpulan data merupakan langkah yang sangat penting dalam penelitian, karena itu seorang peneliti harus terampil dalam mengumpulkan data agar mendapatkan data yang valid. Pengumpulan data adalah prosedur yang sistematis dan standar untuk memperoleh data yang diperlukan. Adapun judul ini, hanya terdiri dari satu variabel saja. Dari waktu variabel itu, peniliti memunculkan empat indikator. Dari keempat indikator itu, peneliti memunculkan lagi 12 pertanyaan kisi-kisi untuk mendapatkan jawaban yang akan mendapatkan hasil penilitian tesis ini. Pertanyaan-pertanyaan yang dipakai peneliti untuk mewawancarai partisipan adalah sebagai berikut:

Tabel 1: Kisi-kisi Pemahaman Kargoisme

\begin{tabular}{|c|c|c|}
\hline Variabel & Indikator & Sub-indikator \\
\hline \multirow{3}{*}{ Kargoisme } & Hakekat kargoisme & $\begin{array}{l}\text { - Menurut saudara bagaimana kargoisme itu } \\
\text { muncul? } \\
\text { - Bagaimana pemahaman saudara tentang } \\
\text { kargoisme itu? } \\
\text { - Menurut saudara bagaimana legenda } \\
\text { manarmakeri itu? } \\
\text { - Apakah ciri-ciri kargoisme yang saudara } \\
\text { ketahui? }\end{array}$ \\
\hline & $\begin{array}{l}\text { Manfaat dan dampak } \\
\text { kargoisme }\end{array}$ & 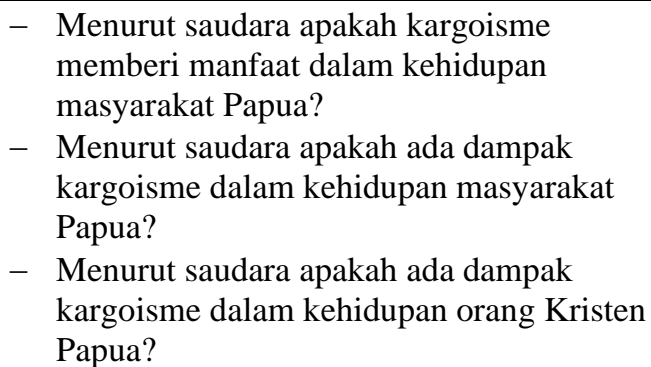 \\
\hline & Praktik kargoisme & 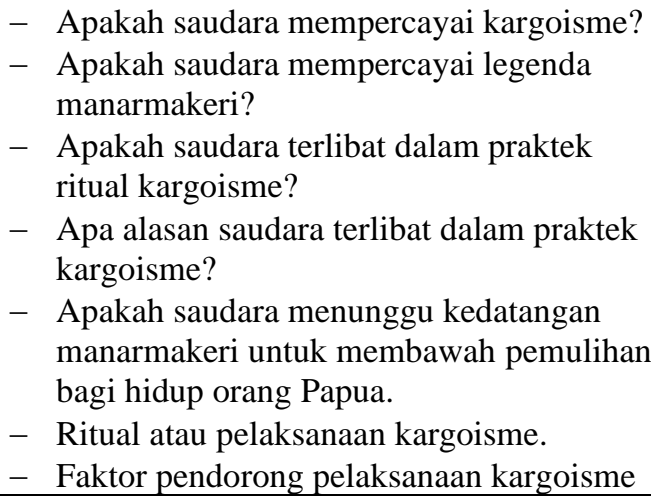 \\
\hline
\end{tabular}

\section{Analisis Data}

Analisis dekskriptif-kualitatif merupakan suatu teknik yang menggambarkan dan menginterpretasikan arti data-data yang telah terkumpul dengan memberikan perhatian dan merekam sebanyak mungkin aspek situasi yang diteliti pada saat itu, sehingga memperoleh gambaran secara umum dan menyeluruh tentang keadaan sebenarnya. Menurut M. Nasir bahwa tujuan deskriptif ini adalah untuk membuat deskripsi, gambaran atau lukisan secara 
sistematis, faktual dan akurat mengenai fakta-fakta, sifat-sifat serta hubungan antar fenomena yang diselidiki. ${ }^{8}$

Secara teoritis pemahaman kargoisme Melanesia di kampung Sorido kabupaten Biak Numfor Provinsi Papua telah dianuti sejak turun temurun secara lisan, dalam aturan-aturan paten, pada budaya di kampung itu. Abstraknya pemahaman kargoisme ini tidak memiliki bukti-bukti konkrit, namun ia memiliki daya dan karisma yang sangat berpengaruh pada pola hidup manusia di kampung Sorido. Pada umumnya di ras Melanesia, juga di seluruh tanah Papua, menganut paham kargoisme yang kuat seperti masyarakt di kampung Sorido kabupaten Biak Numfor Provinsi Papua. Dalam kajian teologi ada dua keinginan luhur untuk memberi pencerahan lewat Firman Tuhan kepada masyarakat kampung Sorido, agar mereka punya kemampuan untuk melihat Yesus sebagai jurus selamat dunia yang tak tertandingi oleh paham kargoisme. Sebab berdasarkan fakta aktual, kepercayaan kepada Yesus Kristus dapat dipertanggung-jawabkan, dan juga bermakna bagi kehidupaan manusia.

Tabel 2: Hasil

\begin{tabular}{|l|l|c|c|c|c|}
\hline \multirow{2}{*}{ No } & \multirow{2}{*}{ Item Pertanyaan } & \multicolumn{4}{|c|}{ Jumlah Jawaban } \\
\cline { 2 - 5 } & $\begin{array}{l}\text { Menurut saudara bagaimana } \\
\text { kargoisme itu muncul? }\end{array}$ & 15 & $93,75 \%$ & 1 & $6,25 \%$ \\
\hline 2. & $\begin{array}{l}\text { Bagaimana pemahaman saudara } \\
\text { tentang kargoisme itu? }\end{array}$ & 15 & $93,75 \%$ & 1 & $6,25 \%$ \\
\hline 3. & $\begin{array}{l}\text { Menurut saudara bagaimana legenda } \\
\text { manarmakeri itu? }\end{array}$ & 14 & $87,5 \%$ & 2 & $12,5 \%$ \\
\hline 4. & $\begin{array}{l}\text { Apakah ciri-ciri Kargoisme yang } \\
\text { saudara ketahui? }\end{array}$ & 16 & $100 \%$ & - & - \\
\hline \multicolumn{1}{|c|}{ Rata-rata } & 15 & $93,75 \%$ & 1 & $6,25 \%$ \\
\hline
\end{tabular}

Dari hasil jawaban dapat diketahui bahwa 93,75\% yang mengetahui awal munculnya kargoisme, sedangkan 6,25\% partisipan tidak mengetahui tentang awal munculnya kargoisme. Kemudian 93,75\% partisipan memahami tentang kargoisme. Sedangkan 6,25\% partisipan tidak memiliki pemahaman kargoisme. Sedangkan 87,5\% memahami legenda manarmakeri dan $12,5 \%$ partisipan tidak memiliki pengertian tentang legenda manarmakeri. Dan akhirnya 100\% partisipan mengetahui ciri-ciri kargoisme.

Tabel 3: Manfaat dan Dampak Kargoisme

\begin{tabular}{|l|l|c|c|c|c|}
\hline \multirow{2}{*}{ No } & \multirow{2}{*}{ Item Pertanyaan } & \multicolumn{3}{|c|}{ Jumlah Jawaban } \\
\cline { 3 - 5 } & Ya & Prosentase & Tidak & Prosentase \\
\hline 1. & $\begin{array}{l}\text { Menurut saudara apakah } \\
\text { kargoisme memberi } \\
\begin{array}{l}\text { manfaat dalam } \\
\text { kehidupan masyarakat } \\
\text { Papua? }\end{array}\end{array}$ & 12 & $75 \%$ & 4 & $25 \%$ \\
\hline
\end{tabular}

${ }^{8}$ Ibid., 58.

Copyright@C 2020, KHARISMATA, ISSN 2655-8645 (online), 2655-8653 (print) | 5 


\begin{tabular}{|l|l|c|c|c|c|}
\hline 2. & $\begin{array}{l}\text { Menurut saudara apakah } \\
\text { ada dampak kargoisme } \\
\text { dalam kehidupan } \\
\text { masyarakat Papua? }\end{array}$ & 15 & $93,75 \%$ & 1 & $6,25 \%$ \\
\hline 3. & $\begin{array}{l}\text { Menurut saudara adalah } \\
\text { ada dampak kargoisme } \\
\text { dalam kehidupan orang } \\
\text { Kristen? }\end{array}$ & 14 & $87,5 \%$ & 7 & $43,75 \%$ \\
\hline & Rata-rata & 13 & $85,47 \%$ & 3 & $14,53 \%$ \\
\hline
\end{tabular}

Merujuk dari hasil jawaban dapat diketahui $75 \%$ partisipan yang merasa kargoisme memberi manfaat dalam kehidupan mereka, sedangkan $25 \%$ partisipan merasa kargoisme tidak memberi manfaat dalam kehidupan mereka. Namun, ada juga 93,75\% partisipan yang merasakan dampak kargoisme dalam kehidupan, dan 6, 25\% partisipan lain tidak merasakan dampak kargoisme dalam kehidupannya. 87,5\% Orang Kristen sebagai partisipan merasa dampak dari kargoisme, dan 43,75\% partisipan sebagai orang Kristen tidak merasa dampak kargoisme dalam hidup mereka.

Tabel 4: Keterlibatan Dalam Praktek Kargoisme

\begin{tabular}{|l|l|c|c|c|c|}
\hline \multirow{2}{*}{ No } & \multirow{2}{*}{ Item Pertanyaan } & \multicolumn{3}{|c|}{ Jumlah Jawaban } \\
\cline { 2 - 5 } 1. & $\begin{array}{l}\text { Apakah saudara } \\
\text { mempercayai } \\
\text { kargoisme? }\end{array}$ & 2 & $12,5 \%$ & 14 & $87,5 \%$ \\
\hline$\quad \begin{array}{l}\text { Apakah saudara } \\
\text { memepercayai legenda } \\
\text { manarmakeri? }\end{array}$ & 14 & $87,5 \%$ & 2 & $12,5 \%$ \\
\hline 3. & $\begin{array}{l}\text { Apakah saudara terlibat } \\
\text { dalam praktek ritual } \\
\text { kargoisme? }\end{array}$ & - & - & 16 & $100 \%$ \\
\hline Rata-rata & 4 & $25 \%$ & 12 & $75 \%$ \\
\hline
\end{tabular}

Berdasarkan hasil jawaban dapat diketahui bahwa 12,5\% partisipan mempercayai kargoisme dan 87,5\% partisipan tidak mempercayai kargoisme. 87,5\% partisipan mempercayai legenda manarmakeri sedangkan $12,5 \%$ partisipan tidak mempercayai legenda manarmakeri. Tidak ada partisipan yang terlibat dalam praktek Kargoisme jadi $100 \%$ partisipan tidak terlibat praktek Kargoisme.

\section{PEMBAHASAN}

\section{Analisis Data}

Sesudah data dikelola dan dideskripsikan, maka langkah berikutnya adalah membahas ciri-ciri dan menjelaskan kargoisme dengan singkat. Dari segi tujuan ini diterapakan analisis dapat juga dipergunakan untuk membahasa secara evaluasi pertanyaan mengapa suatu sistem tidak beroperasi atau bagaimana usaha meningkatkan operasi tersebut. Analisis data tentang pemahan dan keterlibatan masyarakat kampung Sorido kabupaten Biak Numfor Papua tentang kargoisme. 


\section{Hakikat Kargoisme}

Sesudah melalukan pengumpulan data dan mendiskripsikan, maka dilakukan analisis yang menjawab mengenai pemahaman dan keterlibatan masyarakat kampung Sorido tentang kargoisme. Pengertian kargoisme adalah suatu lambang dari berbagai keinginan mutlak yang terdalam, dalam kehidupan melanesia. Gerakan-gerakan kargomelanesia mempunyai suatu pengharapan yang kuat lewat mitos-mitos nenek moyang yang diajarkan secara lisan turun-temurun. Pada dasarnya kesiulan dari pengertian kargo itu adalah suatu kerinduan memiliki hidup yang bebas merdeka dan hidup dalam kelimpahan. ${ }^{9}$

Dari hasil jawaban dapat diketahui partisipan yang menjawab kargoisme muncul dari budaya dan kejadian-kejadian ritual di dalam sebuah suku 43,7\%. Sendangkan 12,5\% kargoisme muncul karena hal-hal ajaib yang muncul di tengah-tengah suatu suku yang di lakukan oleh seseorang 37,5\% berpendapat kargoisme muncul karena berhubungan erat dengan harapan atau impian orang papua untuk suatu kehidupan yang lebih baik, yang ditumbuh kembangkan dalam suatu kebudayan suku 3\% menjawab sangat erat hubungan dengan nilai-nilai keagamaan.

Dari hasil jawaban dapat diketahui partisipan yang menjawab kargoisme lebih merupakan kepercayaan terhadapa leluhur atau cerita dan legenda yang terjadi dalam masyarakat, yang sudah ada sejak dahulu kala 62,5\%. Sedangkan 12,5\% kargoisme hanyalah bagian dari budaya. 6,3\% berpendapat kepercayaan terhadap alam atau seorang yang di anggap sakti. 6,2\% beranggapan kepercayaan terhadap alam atau seseorang yang dianggap sakti. $12,5 \%$ beranggapan kargoisme menurut saya adalah suatu keadaan bahagia dan sering juga dihubungkan dengan kebebasan yang bermakna politis bagi masyarakat Papua.

Dari hasil jawaban dapat diketahui partispan yang menjawab pengertian legenda manarmakeri adalah cerita manarmakeri ini suda ada sejak dulu di dalam suku Biak, yang menggambarkan seseorang yang menderita sakit kulit, namun bertemu dengan seorang dari bintang Fajar (Sampari) dan diberikan kuasa berupa tongkat untuk melakukan hal-hal ajaib yang kemudian pergi kearah barat namun suatu saat akan kembali mengambil harapanharapan baru bagi masyarat Biak Papua 56,35. Sedangkan 12,5\% beranggapan cerita manarmakeri tersebut lebih banyak dipahami oleh para tetua kami. 31,2\% meyakini cerita tersebut ada karena didukung oleh beberapa bukti peninggalan khususnya bagi suku Biak yang dilihat sebagai Tuhan. 31,2\% beranggapan bahwa cerita tersebut ada karena didukung oleh beberapa bukti peningalan khusunya bagi suku Biak yang dilihat sebagai Tuhan.

Dari hasil partisipan dapat diketahui $18,7 \%$ berpendapat bahwa adanya cerita turuntemurun yang dijadikan pedoman kepercayaan. $31,3 \%$ beralasan ada kepercayaan kepada benda-benda tertentu atau kepada hewan-hewan tertentu. $18,7 \%$ berpendapat andanya lagulagu tari-tarian khusus. 6,3\% meyakini adanya tempat-tempat pemujaan berhala, simbol kargoisme seperti kepala suku, panglima perang, pemimpin pujiaan (konor). 25\% berpendapat adanya tempat-tempat pemujaan berhala, simbol kargoisme seperti kepala suku panglima perang, pemimpin pujian (konor).

${ }^{9}$ Robert R. Marini, “Skripsi Sikap Teologia Alkitabiah Menghadapi Sinkritesme Budaya dalam Pertumbuhan Gereja Pantekosta di Indonesia” (Jember: JBC, 1996), 44. 


\section{Manfaat dan Dampak Kargoisme}

Sesudah menghimpun data dan mendiskripsikan, maka hasilnya adalah masyarakat kampung Sorido Kabuaten Biak Numfor Papua dalam manfaat dan dampak kargoisme telah terjadi degradasi yang nyata pada budaya mereka menurut Jorgen Moltmann, janjijanji kepada orang Israel tidak ditinggalkan dalam sejarah Israel, melalui pemenuhan atau kekecewan, tetapi secara terus-menerus diinterpretasikan ulang dalam arti yang lebih luas.

Dari hasil jawaban dapat diketahui 12,5\% meyakini manarmakeri adalah Tuhan itu sendiri, karena itu mirip cerita dalam Alkitab. 50\% beranggapan tidak ada manfaatnya, karena banyak yang dilakukan seperti membuat persembahan tetapi tidak ada berkat yang didapat. $12,5 \%$ beralasaan Manfaatnya seperti menolong suku biak keluar dari bahaya, membuat hujan, menangkap ikan. 6,3\% beranggapan manfaatnya seperti menolong suku Biak keluar dari bahaya, membuat hujan, menangkap ikan. 18,7\% meyakini orang-orang yang percaya pada manarmakeri ini banyak berharap pada koreri yaitu suatu kehidupan seperti di surga.

Dari jawaban responden, diketahui bahwa 6,5\% reesponden menjawab bahwa telah terjadi kepercayaan-kepercayaan baru di tengah masyarakat. Sedangkan 12,5\% responden berpendapat bahwa dampaknya tidak begitu jelas, tetapi setelah orang Papua mendengar tentang Injil Kristus maka yang menyamakannya dengan Tuhan. 12,5\% juga beranggaapan bahwa banyak masyarakat Papua yang masih hidup dalam praktek-praktek olkutisme, seperti penyebahan terhadap batu atau pohon. $56,25 \%$ beryakinan bahwa yang bertaian dengan budaya dan prinsip-prinsip dasar orang Papua berasal dari kargoisme. 5,6\% partisipan mengakui bahwa di Numfor, seorang penginjil pernah di bunuh oleh karena memberitakan Injil, sebab dianggap menentang kepercayaan kargoisme. Sedangkan 5,6\% berpendapat bahwa kepercayaan yang tumbuh dalam masyarakat Papua memiliki nama yang berbeda-beda, baik daerah pantai dan pegunungan tetapi yang mengerankan ceritanya tidak jahu berbeda. Semua percaya bahwa nantinya akan ada kehidupan yang lebih baik.

Dari jawaban responden dalam tabel di atas tentang dampak kargoisme bagi kehidupan orang Kristen Papua 56,25\% (9 orang) memahami bahwa kargoisme tidak begitu berdampak bagi kehidupan orang Kristen. 37,5\% (6 orang) di antaranya memahami bahwa kargoisme banyak mempengaruhi iman orang Kristen sehingga membuat Injil susah untuk menebus hati orang-orang Papua. Sedangkan 6,26\% (1 orang) menjawab bahwa dampak kargoisme menjadi suatu tantangan bagi orang Kristen Papua.

Dari hasil jawaban 16 partisipan tentang apakah reponden mempercayai kargoisme, dapat diketahui bahwa 14 responden atau 87,5\% menolak untuk mempercayai kargoisme. Sebab bagi mereka, kargoisme dilihat sebagai sebuah legenda, meski kargoisme sangat kental dalam orang Papua. Sedangkan 2 orang di antaranya atau 12,5\% masih mempercayai kargoisme. Sebab bagi kedua orang itu, menjawab bahwa mungkin sedikit dari nilai-nilai kargoisme yang masih mereka lakukan. Seperti, menghormati daerah/wilayah yang diklaim sebagai tempat leluhur. 


\section{Keterlibatan dalam Praktik Kargoisme}

Sesudah mengumpulkan data dan mendiskripsikan, maka dilakukan analisis yang menjawab tentang pemahaman dan keterlibatan masyarakat kampung Sorido Kabupten Biak Numfor Papua terkait dengan kargoise J.Verkuy menyatakan dalam bukunya "Etika Kristen dan Kebudayaan" bahwa ada hubungan antara agama-agama dan kebudayaan tampaknya dengan jelas di dalam sejarah betapa agama-agama telah mempengaruhi kebudayaan-kebudayaan dan sebaliknya, betapa kebudayaan-kebudayaan yang ada telah mempengaruhi agama-agama. ${ }^{10}$

Mengenai kepercayaan-kepercayaan terhadap manarmakeri, dari hasil wawancara kepada 16 responden, yang menjawab benar legenda manarmakeri adalah sebuah cerita yang benar-benar ada sebab mereka mengaku bahwa mereka melihat sendiri bukti-bukti yang ditinggalkan di pulau Yobi berjumlah 14 orang atau dalam perhitungan porsentase adalah $87,5 \%$. Sedangkan 2 orang diantaranya atau 12,2\% menjawab bahwa legenda manarmakeri benar ada sebab, sampai hari ini sering diceritakan dan masyarakat juga masih menghubungkannya dengan keadaan yang terjadi di sekitar mereka. Keterlibatan keenam belas partisipan semuanya $100 \%$ menolak bahwa mereka tidak terlibat dalam praktek ritual kargoisme.

Pertanyaan wawancara tentang pengharapan kedatangan manarmakeri dinyatakan kepada 16 responden, dan 4 orang atau $25 \%$ di antaranya menjawab bahwa mereka percaya sebab sebagian bukti sejarahnya masih ada, bahkan satu generasi di atas saya berkata pernah bertemu langsung dengan manarmakeri. Sedangkan 12 orang lainnya (75\%) tidak sependapat karena mereka sudah percaya kepada Yesus Kristus. Pada tabel terakhir, alasan keterlibatan responden praktek kargoisme, mereka tidak terlibat dalam praktek sebab keenam belas responden itu, 100\% sudah percaya kepada Yesus Kristus.

\section{Interpretasi Data}

Setelah seluruh indikator di atas dideskripsikan dan dianalisis, maka dapat disampaikan bahwa nilai pemahaman masyarakat kampung Sorido kabupaten Biak Numfor Provinsi papua tentang kargoisme adalah tinggi. Sebab dari perhitungan persentase yang paling tinggi mengenai pemahaman mereka tentang kargoisme adalah 62,5\% yang paham benar tentang apa itu kargoisme. Itu dapat diartikan bahwa masyarakat kampug Sorido kabupaten Biak Numfor Provinsi Papua memahami tentang apa yang dimaksud dengan kargoisme, yaitu asal usulnya ciri-cirinya, legenda manarmakeri manfaatnya, dan dampak kargoisme bagi kehidupan mereka.

Sedangkan tentang keterliatan masyarakat kampung Sorido kabupaten Biak Numfor provinsi Papua tentang kargoisme dari hasil deskripsi dan analisis data, dapat disampaikan bahwa nilai nilai ketidakterlibatan masyarakat kampung Sorido kabupaten Biak Numfor Provinsi Papua tentang kargoisme adalah sangat tingi, dengan perhitungan porsentasenya adalah $100 \%$. Jadi ke 16 responden itu sama sekali tidak terlibat dalam kepercayaan kargoisme, kepercayaan terhadap legenda manarmakeri, keterlibatan terhadap praktek ritual

${ }^{10}$ J. Verkuyl, Etika Kristen dan kebudayaan (Jakarta: BPK Gunung Mulia, 1990), 17-18. 
kargoisme, menanti kedatangan manarmakeri, dan keterlibatan dalam hal apapun tentang kargoisme itu.

Suatu gerakan kargoime yang klasik, biasanya dimulai dengan suatu pengumuman oleh seorang nabi atau seorang pemimpin yang menyatakan bahwa ia telah mendapat suatu penglihatan atau mimpi dimana di dalamnya ia mendapat informasi tentang nenek moyang yang akan datang kembali dalam waktu yang tidak lama lagi.Wahyu itu meramalkan bahwa kedatangan para leluhur didahului tanda-tanda yang jelas, seringkali berupa perubahanperubahan yang besar. Mungkin berupa suatu gempa bumi atau banjir, gelombang air pasang, atau tanda-tanda lain yang akan terlihat pada matahari dan bulan atau kegelapan yang maha besar yang akan menutupi bumi.

Sesudah nabi memberi pengumuman dan ramalan-ramalannya, warga-warga kampung akan mengikuti nabi tersebut dalam rangkaian kegiatan-kegiatan tertentu. Semua pekerjaan sehari-hari mereka hentikan secara tiba-tiba, binatang peliharaan seperti babi dan ayam dibunuh habis sama sekali, harta kekayaan dan hasil kebun dibongkar dan dihancurkan semuanya dengan tujuan untuk mempercepat kedatangan roh-roh orang mati yang akan membawa serta sejumlah kargo. Seringkali mereka membangun gudang-gudang yang besar untuk menyimpan barang-barang baru yang di harapkan tiba secara berkelimpahan. Akhirnya kuburan-kuburan dibersihkan diikuti oleh persiapan-persiapan untuk mengadakan pesta-pesta. Orang telah mati akan datang mengambil bagian dan duduk menikmati pesta bersama-sama dengan yang hidup.

Ketika meneliti pengharapan orang Papua di dalam kargoisme maka pantas bagi peneliti untuk menampilkan mesianis di dalam kekristenan dengan fakta-fakta alkitabiah yang layak diimani dan diteladani. Ada beberapa pandangan para teolog secara kronologis tentang "Mesias" yang dikaitkan dengan kedudukan seorang raja sebagai "Imam Besar" yang memerintah Israel. Menurut peneliti, pengharapan Mesias juga bersumber dari nubuatan para nabi. Pada dasarnya Perjanjian Lama juga dikisahkan Israel sebagai bangsa Allah melalui panggilanNya, pada akhirnya bangsa Israel menolak kedatangan Yesus Kristus sebagai Mesias, sehingga kitapun dianugrahi menjadi bangsa pilihan Allah.

\section{KESIMPULAN}

Dengan berorientasi pada tujuan penelitian, deskripsi analisis data, dan interpretasi yang telah dijelaskan sebelumnya, maka berikut ini akan disimpulkan hasil pemahaman dan keterlibatan masyarakat kampung Sorido kabupaten Biak Numfor Papua tentang kargoisme adalah: Masyarakat kampung Sorido kabupaten Biak Numfor Provinsi Papua 62, 5\% yang paham benar tentang apa itu kargoisme. Itu dapat diartikan bahwa masyarakat kampung Sorido kabupaten Biak Numfor Provinsi Papua memahami tentang apa yang dimaksud dengan kargoisme, yaitu asal usulnya ciri-cirinya, legenda manarmakeri manfaatnya, dan dampak kargoisme bagi kehidupan mereka. Keterlibatan masyarakat kampung Sorido kabupaten Biak Numfor Provinsi Papua tentang kargoisme dari hasil deskripsi dan analisis data, dapat disampaikan bahwa mereka tidak terlibat dalam praktek kargoisme karena sudah percaya Yesus, dengan perhitungan porsentasenya adalah $100 \%$. 
Perlu adanya kepedulian dari gereja, dan para teolog dalam pemberitaan Injil yang benar dan penuh kuasa. Pemahaman kargoisme yang kental dalam diri orang Papua, perlu di dekati dengan strategi jitu yang berpedoman pada pemberitaan Injil linta budaya yang kontekstual, dengan harapan terjadi perubahan paradigma kargoisme kepada hidup baru yakni berkarakter Kristus. Perlu adanya adaptasi-adaptasi antropologi sosial budaya yang bersifat Rohani kepada masyarakat penganut kargoisme. Perlu adanya pendalaman Alkitab (PA) bagi para Pendeta agar mereka memiliki hati seperti Yusuf untuk membaktikan dirinya di tengah-tengah masyarakat penganut kargoisme. Gereja-gereja harus mengambil inisiatif untuk meng-introspeksi diri, khususnya dalam hubungannya dengan sikap dan perlakuan mereka terhadap pengikut-pengikut kargoime. Gereja-gereja perlu membenahi diri dan memiliki strategi-strategi terbaik untuk kemenangan berita bInjil pada komonitas kargoisme. Gereja-gereja harus lebih awal belajar tentang kargoisme melanesia, agar lebih mengerti titik persoalan dan juga tahu jalan keluar lewat pemberitaan Injil.

\section{REFERENSI}

Alkitab Penuntun Hidup Berkelimpahan. Malang: Gandum Mas, 2000.

Amtiran, Abdon A. "Memahami Missio Dei Sebagai Suatu Perjumpaan Misioner Dengan Budaya.” MAGNUM OPUS: Jurnal Teologi dan Kepemimpinan Kristen 1, no. 1 (2019): 13-21.

F. C. Kamma. De Mesiaanic Koreri-Bewegingen in het Biaks- Noemfoorse. Den Hag: Culturgebied, 1954.

Hannas, and Rinawaty. "Menerapkan Model Penginjilan Pada Masa Kini." Kurios 5, no. 2 (2019): 175-189.

Ibraim Peyon. Manusia Papua Negroid. Jakarta: Kelompok studi Nirentohon PT. Kreatama, 2012.

J. Vekuyl. Etika Kristen dan Kebudayaan. Jakarta: BPK Gunung Mulia, 1990. Jurgen Moltmann. Teologi Mesianis. Jakarta: PBK Gunung Mulia, 1993.

Mansoben J. R. "Sistem Politik Tradisional Etinis Byak” Jurnal Antropologi Papua. Jakarta: Volume 1. No. 3 April, 2003.

Mansoben J. R. Sistem Politik Tradisional di Irian Jaya. Jakarta: LIPI-RUI,1995.

Peyon A. Ibrahim. Kolonialisme dan cahaya Dekolonialisasi di papua Barat. Jayapura: Nentien Fokus, tt.

Robby Marini. Skripsi: Sikap Teologia Alkitabiah Menghadapi Sinkretisme Budaya dalam Pertumbuhan Gereja Panteskosta di Indonesia. Jember, 1996.

Robert J. Schreiter C. PP. S. Rancang Bangun Teologi Lokal. Jakarta: PBK Gunung Mulia,1996.

Siahaya, Johannis. "Misi Dalam Doa Yesus Menurut Yohanes 17.” Jurnal Teruna Bhakti 1, no. 2 (2019): 19-20. http://ejournal.stakterunabhakti.ac.id/index.php/teruna/issue/archive.

Tari, Ezra. "Teologi Tongkonan : Berteologi Dalam Konteks Budaya Toraja." EPIGRAPHE: Jurnal Teologi dan Pelayanan Kristiani 2, no. 2 (2018): 93-102. http://www.stttorsina.ac.id/jurnal/index.php/epigraphe.

Widjaja, Fransiskus Irwan. Misiologi Antara Teori, Fakta Dan Pengalaman. 1st ed. Yogyakarta: Andi Offset, 2018.

Widjaja, Fransiskus Irwan. "Papua Dan Panggilan Macedonia Di Zaman Millennium Baru.” DIEGESIS: Jurnal Teologi Kharismatika 2, no. 1 (2019): 35-38. 
Widjaja, Fransiskus Irwan. "PLURALITAS DAN TANTANGAN MISI : KERANGKA KONSEPTUAL UNTUK PENDIDIKAN AGAMA.” Regula Fidei: Jurnal Pendidikan Agama Kristen 4, no. 1 (2019): 1-13.

Widjaja, Fransiskus Irwan, Daniel Ginting, and Sabar Manahan Hutagalung. "Teologi Misi Sebagai Teologi Amanat Agung.” THRONOS: Jurnal Teologi Kristen 1, no. 1 (2019): $17-24$.

Wiryadinata, Halim. "Mission And Evangelism: African Context." KURIOS (Jurnal Teologi dan Pendidikan Agama Kristen) 3, no. 1 (2015): 1-11. http://www.sttpb.ac.id/e-journal/index.php/kurios.

Yakobus F. Dumupa. Berburu Keadilan di Papua. 